Article

\title{
Sinai Trafficking: Origin and Definition of a New Form of Human Trafficking
}

\author{
Mirjam van Reisen ${ }^{1}$ and Conny Rijken ${ }^{2, *}$ \\ ${ }^{1}$ School of Humanities, Tilburg University, 5000 LE Tilburg, The Netherlands; E-Mail: m.vanreisen@uvt.nl \\ ${ }^{2}$ Intervict (International Victimology Institute), Tilburg Law School, 5000 LE Tilburg, The Netherlands; \\ E-Mail: c.r.j.j.rijken@uvt.nl \\ * Corresponding author
}

Submitted: 2 September 2014 | In Revised Form: 12 December 2014 | Accepted: 19 December 2014 |

Published: 23 February 2015

\begin{abstract}
The phenomenon that is coined "Sinai Trafficking" started in 2009 in the Sinai desert. It involves the abduction, extortion, sale, torture, sexual violation and killing of men, women and children. Migrants, of whom the vast majority are from Eritrean descent, are abducted and brought to the Sinai desert, where they are sold and resold, extorted for very high ransoms collected by mobile phone, while being brutally and "functionally" tortured to support the extortion. Many of them die in Sinai. Over the last five years broadcasting stations, human rights organisations and academics have reported on the practices in the Sinai and some of these reports have resulted in some confusion on the modus operandi. Based on empirical research by the authors and the analysis of data gathered in more than 200 recorded interviews with Sinai hostages and survivors on the practices, this article provides a definition of Sinai Trafficking. It argues that the term Sinai Trafficking can be used to differentiate a particular new set of criminal practices that have first been reported in the Sinai Peninsula. The article further examines how the new phenomenon of Sinai Trafficking can be framed into the legal human trafficking definition. The interconnectedness of Sinai Trafficking with slavery, torture, ransom collection, extortion, sexual violence and other severe crimes is presented to substantiate the use of the trafficking framework. The plight of Sinai survivors in Israel and Egypt is explained to illustrate the cyclical process of the trafficking practices especially endured by Eritreans, introduced as the Human Trafficking Cycle. The article concludes by setting out areas for further research.
\end{abstract}

\section{Keywords}

Egypt; Eritrea; human trafficking; Human Trafficking Cycle; international organized crime; Israel; refugees; Sinai

\section{Issue}

This article is part of the special issue "Perspectives on Human Trafficking and Modern Forms of Slavery", edited by Siddharth Kara (Harvard Kennedy School of Government, USA).

(C) 2015 by the authors; licensee Cogitatio (Lisbon, Portugal). This article is licensed under a Creative Commons Attribution 4.0 International License (CC BY).

\section{Introduction}

The Sinai desert is historically known as an area where human trafficking and the slave trade take place, with the intention to sell human beings to international markets of exploitative labour. In 2009 the nature of the trade in human beings in Sinai changed. The financial benefit of the human trafficking transformed into forced begging under pressure of torture and threats of killing, in exchange for the release of the hostage itself. The availability of mobile phones played a crucial role in the ransom collection. In Europe, the phenomenon was first identified by father Zerai Mussie, a Rome-based catholic priest of Eritrean descent, who had been contacted by hostages in Sinai who were asking for help in the collection of ransom for their release. He addressed the prob- 
lem at a hearing in the European Parliament in Brussels on 29 November 2010 (European Parliament, 2010). Hostages had contacted the priest by mobile phone to ask for his help. Radio-journalist Meron Estefanos, a Swedish Eritrean, contacted several hostages and recorded the interviews. With the consent of the hostages who were still in captivity, these interviews were broadcast in Tigrigna, the principal language of refugees from Eritrea, in early 2011 on the radio channel Voice of Meselna Delina (VoMD, 2011), which targeted Eritrean communities in Eritrea, refugee-camps and elsewhere. The first radio broadcast was posted on the Tigrigna/English website Asmarino on 3 March 2011. This website targets an audience of Eritreans in the diaspora. The comments sparked mostly negative messages from Eritrean pro-government supporters.

This article aims to give a clear definition of Sinai Trafficking. It begins with a description of the original confusion in the media of what constitutes the problem of Sinai Trafficking. It sets out the research conducted by the authors and describes the modus operandi, which emerged from the data-analysis in Section 2. It then interprets the modus operandi and defines a new form of human trafficking, coined Sinai Trafficking. It is argued that this is a new and specific form of trafficking, which has not been earlier described in extant academic literature. The combination of severe forms of crimes and new forms of trafficking, namely, trafficking for forced begging and ransom makes Sinai Trafficking distinct from other trafficking practices anywhere in the world (Section 3). The article describes the cyclical nature of the Sinai Trafficking and briefly analyses the plight of Sinai survivors in Egypt and Israel (Section 4). The article will finally address the definition of Sinai Trafficking and the ramifications of the findings for future research.

\section{The Initial Contradictions in the Definition of "Sinai Trafficking"}

This section sets out when and where Sinai Trafficking was discovered as a phenomenon and how it was initially described (Carr, 2011). The aim of this description is to trace the origin and to explain the confusion that originally arose on these new practices that emerged from 2009 onwards in Sinai. It describes how the issue was identified, when and how it was linked to a targeted group (Eritreans) and it describes how it was initially linked in the media to organ trafficking. The link to organ sales reported in the media has not been confirmed by research findings. This description forms the background against which the need for a clear evidence-based definition of the trafficking in the Sinai is argued.

\subsection{Origin of a New Practice of Trafficking in Sinai}

The first to describe the problem was Tel Aviv based
Physicians for Human Rights (PHR) also referred to as PHR-Israel (2010a). PHR-Israel provides free medical assistance to refugees, and its staff had observed a vast increase in refugees coming through the Sinai, with particular patterns of torture and among whom were many women who seemed in need of abortion. The organisation started to systematically interview the patients and between 12 October and 7 December 2010, PHR-Israel interviewed a total of 167 individuals from Eritrea and Ethiopia, Sudan and six other countries, including 108 men and 59 women, ranging in age from 19 to 66. It found that Eritreans (and Ethiopians) were particularly subjected to torture. On 28 November 2010, PHR-Israel (2010b) communicated publicly that they were dealing with a new challenge: "According to repeated accounts, groups of approximately 200-300 Eritreans are brought to Sinai where they are held in metal containers or compounds. Captives undergo torture by burning or beating, as smugglers call their relatives demanding the immediate transfer of funds to be guaranteed transit to the Israeli border. A consequence of the high ransom price is that it often takes weeks or even months for refugees to be taken to the border. It is during this time that women are separated from the group, detained in secluded rooms and subjected to repeated sexual acts, abuse, and rape at the hands of their captors".

On 3 December 2010, PHR reported that the ransoms were going up. In a subsequent report there was no differentiation between Eritreans and Ethiopians, the number of the survey report stated that out of 284 patient interviews with disproportionate torture, $80 \%$ originated from Eritrea. From the documentation it is clear that the disproportionate presence of Eritreans in the population was not yet "noted" despite the significance of Eritrean presence appearing in the data (Physicians for Human Rights, 2011). In April 2012 PHRIsrael published a report together with the Israel-based Hotline for Migrant Workers in which findings of data analysis of 682 patient interviews were presented (Hotline for Migrant Workers, 2012). The briefing paper drew attention to the inadequate response by Egyptian and Israeli authorities to provide protection, and reported that 178 out of 682 survivors had stated that they had been shot at on the Israeli-Egyptian border.

\subsection{Linking Sinai Trafficking to Eritrea and the Abduction of Human Beings as Commodities}

Mekonnen and Estefanos (2012) and Humphris (2012) described a link between the deplorable human rights situation in Eritrea and the proportion of Eritreans among Sinai Trafficking victims. Van Reisen, Estefanos, \& Rijken (2012) reported that victims were predominantly of Eritrean origin (95\% of all hostages). In 2014, Human Rights Watch made an even more specific connection to Eritreans as victims of the Sinai Trafficking, 
entitling their report "I wanted to lie down and die. Trafficking and Torture of Eritreans in Sudan and Egypt". Human Rights organisations have increasingly pointed to the forced military conscription in Eritrea combined with the severe conditions with regards to rule of law, human rights and governance as well as the lack of economic opportunities, rampant poverty and lack of freedom as a lethal cocktail which produces vast numbers of refugees. Van Reisen et al. (2012) linked the origin to the crisis in Sinai of Eritrean refugees to the increasing vulnerability of Eritrean refugees in countries neighbouring Eritrea and the agreement between the Italian and Libyan governments to return refugees, leading to fear of deportation from Libya by Eritrean refugees. Looking for alternative routes, Israel came in sight as a destination, reachable through the Sinai. The effective payment of originally relatively low ransom increased the "business" potential of human commodification and resulted in an increasing "investment" by organized criminal organisations in order to develop the structure of the "business". This led to a new model in which the abduction of human beings as commodities became a feature. The UN High Commissioner for Refugees pointed to the lack of security in refugee camps in Sudan as early as 2012 in relation to the increasing number of abductions from the camps. The extent to which the abduction of human beings as commodities has penetrated Eritrea remains a question for further research. Van Reisen, Estefanos, \& Rijken (2014) describe the abduction from within Eritrea and the UN Monitoring on Somalia and Eritrea Report $(2012,2013)$ and Human Rights Watch (2014) discovered that Eritrean military are engaged in the smuggling and trafficking of Eritrean citizens. The exact nature of the relationship between smuggling, trafficking and abduction from within Eritrea needs to be further examined in order to understand the scale and the responsibility of the Eritrean military and government in the trafficking.

\subsection{The Disputed Dimension of Organ Trafficking}

Meanwhile, the broadcast of a documentary on trafficking in the Sinai by the Egyptian TV channel, YOUM7TV on 31 October 2011 included graphic photos and suggested that human trafficking was connected to organ trafficking. An English reference to this report appeared in the Egypt Independent in December 2011. In a translation of the Youm7 report in English cited by Mekonnen and Estefanos (2012) the report claimed that "Those who are unable to pay the ransom face a number of horrendous violations such as torture, electrocution, rape and other forms of violations. Some have suffered removal of organs to settle the ransom. As revealed by the Egyptian daily newspaper Youm7 the traffickers are equipped with sophisticated techniques of organ harvesting which implies that they have the support of medical personnel involved in this illicit activity. Once organs are extracted from victims they are injected with anaesthesia and preserved in a refrigerator to help prolong their viability. According to Youm7, evidence in this regard was collected from a car crash, which involved the death of a doctor (possibly also a trafficker) who was travelling with mini refrigerators containing human organs". On 3 November 2011 CNN published an article by Pleitgen (2011) reporting human trafficking in Sinai being linked to organ trafficking based on reports of The New Generation Foundation for Human Rights and the EveryOne Group from Italy. The article was based on "evidence that the bodies of African refugees have been found in the Sinai desert with organs missing". The article claimed that Al-Azazy, director of the New Generation Foundation, had stated that the organs are taken from refugees while they are still alive: "The organs are not useful if they're dead. They drug them first and remove their organs, then leave them to die and dump them in a deep dry well along with hundreds of bodies". According to the CNN article, Al-Azazy claimed that "Mobile clinics using advanced technology come from a private hospital in Cairo to an area in the deserts of Mid-Sinai and conduct physical examinations on the Africans before they choose those who are suitable, then they conduct the operation". In Pleitgen's report details of the organization of the organ-removal were provided, based on similar evidence as the Youm7 report. During a closed meeting in the European Parliament, the same photographs showing corpses with cuts in the lower body-used as evidence in the TV documentaries of Youm7 and CNN-were shown by Alganesh Fessaha, alias Dr. Alganesh, from the Gandhi Foundation. On 19 November 2011, CNN broadcasted the documentary Death in the Desert, which was based on the same evidence (CNN, 2011). This documentary was later awarded the Tom Renner Award for its "investigative coverage of organized crime". Another CNN documentary followed in September 2012; A Stand in the Sinai maintained that "These traffickers then tortured the refugees, and in some cases harvested their organs for sale on the black market, leaving many of their victims to die" (CNN, 2012).

The European Parliament adopted a "European Parliament resolution on Human trafficking in Sinai, in particular the case of Solomon W." on 13 March 2012. The resolution also refers to "human organ traffickers" (F). The resolution had been initiated through advocacy by the EveryOne Group. While the version initially tabled referred to organ trafficking, the final version adopted refers only to the statement of Solomon W. that "one of the jailers showed him a plastic bag containing human organs of a refugee who did not pay the ransom" (E). It should be noted that the identity of Solomon W. presented as a victim in the resolution was disputed by some experts on Sinai Trafficking (van Reisen et al., 2012). 
In March 2012 a coalition of organisations issued a report. The group included Israel based organisations: Physicians for Human Rights-Israel, the Hotline for Migrant Workers and several groups and individuals organized to address problems related to Eritrean refugees, among them Agenzia Habeshia, the International Commission on Eritrean Refugees, The America Team for Displaced Eritreans, Eritrean Movement for Democracy and Human Rights, and Release Eritrea (van Reisen et al., 2012). This report (Physicians for Human RightsIsrael et al., 2012) does not elaborate on the earlier mentioned alleged connection to organ trafficking and it also did not specifically identify the hostages as Eritreans. However, the report cited several cases that were filed by Eritreans with the police related to extortion, torture and kidnapping. The publication by van Reisen et al. stated that "the threat of organ harvesting and death is part of the pattern of torture regularly described in the interviews" (van Reisen et al., 2012, p. 4), but it did not link Sinai Trafficking to forced removal of organs or any commercial organ trade. With regards to the issue of the practice of organ trade and trafficking for the removal of organs, no research has been published that provides any evidence of the presumed link made by some media that links the commodification of human beings in Sinai to trafficking for the removal of organs and commercial organ trade. Van Reisen et al. (2012) only confirmed through their research that there was the threat of organ removal for sale but found no evidence of actual organ sale.

\section{Modus Operandi and Definition of "Sinai Trafficking"}

In this section we present the empirical data collected for the research on modus operandi of the traffickers in the Sinai, resulting in a definition of the specificity of Sinai Trafficking. The section is concluded with the legal framing of the practice into the definitions of Trafficking in Persons and Slavery.

\subsection{The Set-Up of the Research}

Research on which this article is based was carried out in two phases. The first analysis was based on 123 interview recordings carried out between 2010 and 2012 (analysis published in 2012). Interviews with Sinai hostages were conducted mostly through skype to mobile phones and these interviews were recorded. The second study was based on a total of 115 interview recordings of which 77 contain information directly related to the modus operandi of the traffickers in the Sinai. Interviews from the second research were carried out with hostages while they were held in the Sinai and afterwards in their various situations: escaped in the Sinai, in detention in the Sinai, released in the Sinai and released in Cairo. In addition, Sinai survivors who had been able to enter Israel (before the fence was completed on the Egypt-Israel border) were interviewed in Tel Aviv in face-to-face interviews. These interviews were conducted in Tigrigna. The interviews were transcribed and translated into English. The original contact was usually established by the researchers following approaches from victims or families of hostages. Once contact was established a snow-balling technique was used to record the stories of victims held within the same group. The interview transcripts were analysed by coding the information and comparing these. Two different methods for coding-counts and comparisons-were used by two different research-coding groups. The information of the two groups were compared. Interviews with resource people were held to provide context for the interpretation of the interviews and to detail the code-headings. Results of the analyses were compared with other research sources, especially analysis of interviews carried out by PHR-Israel and by the Hotline for Migrant Workers.

\subsection{Results of the Research}

The purpose of the analysis of the interviews was to establish a clear understanding of the new form of trafficking in the Sinai. The modus operandi of the traffickers include four main elements: (1) Involvement of officials in the smuggling, abduction and trafficking during the route to Sinai; (2) the captivity, torture and extortion in Sinai; (3) the killing of hostages in Sinai; and (4) the organization of the Sinai Trafficking. These elements are discussed below where the first element is also addressed in the section on the organization of the Sinai Trafficking. We start with a section on the involvement of officials in Sinai Trafficking

\subsubsection{Involvement of Officials in Sinai Trafficking}

The involvement of Eritrean, Sudanese and Egyptian military and security personnel in the smuggling, abduction and trafficking has been described in several reports. In its reports the UN Monitoring Group on Somalia and Eritrea $(2011,2012,2013)$ has pointed to the role of Eritrean military leaders in the organization of smuggling and trafficking of Eritrean citizens. In van Reisen et al. $(2012,2014)$ the involvement of military and security personnel of these three countries is described. Van Reisen et al. also describe the violent pushbacks from the Israeli military and hand-over of Sinai Trafficking victims to Egyptian military (2014, pp. 99-102). Human Rights Watch concluded that "In some cases, these crimes are facilitated by collusion between traffickers and Sudanese and Egyptian police and the military who hand victims over to traffickers in police stations, turn a blind eye at checkpoints, and return escaped trafficking victims to traffickers" (2014, p. 4). Van Reisen et al. (2014) and Human Rights Watch 
(2014) describe the collusion of soldiers, police and security forces in Eritrea, Sudan and Egypt and their collusion with the traffickers. The collusion includes reports of victims of trafficking being detained and traffickers set free (Human Rights Watch, 2014; van Reisen et al., 2014).

\subsubsection{Captivity, Torture and Extortion in Sinai}

Based on the analysis of the interviews, "Sinai Trafficking" is defined as a new form of commoditisation of human beings "which is particularly brutal and is characterised by abduction, displacement, captivity, extortion, torture, sexual violence and humiliation, serial selling and killing. The 'trafficking' aspect of the phenomenon involves the taking of people against their will or by misleading them and holding them as hostages for ransom or further sale. The torture undertaken as part of the Sinai Trafficking is cruel and frequent and is used to force the hostages to initiate contact with relatives or friends in order to collect the ransom. Contact takes place using mobile phones. The torture is often applied while the telephone conversations are taking place to pressure contacts into paying the ransom. The torture is functional, but also gratuitous and sadistic. Sexual violence, rape and group rapehumiliating acts of violence that undermine the dignity and self-esteem of the hostages and leave them with lifelong emotional and physical injuries-are frequent. Women and young girls are especially targeted for sexual-based violence. These acts of violence contribute to the commoditisation of the hostages by denuding them of human qualities" (van Reisen et al., 2014, pp. 23-24). The sexual violence is not limited to women and girls only and also involves men and boys.

In research published by van Reisen et al. (2012, 2014), Amnesty International (Al) (2013) and Human Rights Watch (2014) the elements of the modus operandi in Sinai were described. Amnesty International published an overview of the methods applied in the torture in Sinai: "Most commonly reported methods of violent treatment include beatings with various objects such as metal chains, sticks and whips; burning with cigarette butts or heated rubber and metal objects; suspension from the ceiling and suspension in contorted positions for prolonged periods of time; pouring gasoline over the body and setting it on fire; and being forced to stand for extended periods of time in desert heat. Some victims have reported that they were given electric shocks, or had seen others held captive with them subjected to electric shocks. Others reported being urinated on and having fingernails pulled out. Rape of men and women, and other forms of sexual violence have been frequently reported" (AI, 2013, p. 12). The description contains similar elements as the one provided in van Reisen et al. (2012) and the more detailed summary list of torture practices in van Reisen et al.
(2014, pp. 74-75), which also includes forced use of drugs. The trauma is severe, and the rape and sexual violence, the loss of body parts, burns and electrocution and mental abuse and torture, result in life-long physical and psychological trauma.

\subsubsection{Killing of Hostages in Sinai}

The frequent death of hostages held in captivity in Sinai has been documented on the basis of interviews with victims in Sinai by van Reisen et al. $(2012,2014)$ and by Human Rights Watch (2014) based on interviews with survivors. Death can result from the severity of the torture. There are also reports of direct killing by beating, cutting, shooting or setting hostages to fire. The death of hostages does not stop kidnappers from collecting ransoms. This results in ransoms being paid for hostages who have already died or who have disappeared, perhaps due to unsafe release (van Reisen et al., 2014). Threats to remove and sell organs add to the stress exercised over hostages. The dumping of bodies in the desert, where they are not buried and where they are left to rot or to be taken by animals, and the lack of dignity resulting from this, adds to the torture of Sinai victims.

\subsubsection{Organization of the Sinai Trafficking}

The practices of Sinai Trafficking can be described as slavery. After being abducted or recruited otherwise in Eritrea or Sudan and transported to Sinai by car, the hostages arrive in a "warehouse", where the salesprice is set based on a number of parameters. The price of Eritrean nationals is higher than the price of other nationalities and Ethiopians are forced to say that they are Eritrean, so that their selling price is increased. Bedouin traffickers select the hostages and take them to different locations. In terms of the ransom collection and the negotiations with family members, relatives and hostages, different patterns occur with the different trafficking groups. Also the cruelty of torture varies. The setting of prices is also different between the groups. Once ransom has been paid, hostages are regularly sold on to another group, where they have to collect ransom again (van Reisen et al., 2012, 2014). Hostages are also forced to participate in forced labour (Human Rights Watch, 2014). Ransom is collected through phone calls with family members, relatives or others; when phone calls are made, the hostages are tortured to add pressure to the extortion. Torture may follow certain patterns and schedules. Sexual violence, rape and gang rape are regular and conducted with severe cruelty and many women become pregnant from rape, even resulting in birth (forced pregnancy). The birth of babies increases and sometimes doubles the price of ransoms. The hostages are of all ages, including the elderly, minors, young 
children and babies. All persons held hostage, including pregnant women and all other vulnerable persons, such as mentally or physically seriously ill people, could be subject to severe torture without distinction. There is no medical support.

Part of the structure of the organization of the Sinai Trafficking is the impunity of the traffickers, especially those who organise the trade. Instead, there have been published reports of victims of trafficking being detained by police officers, who let the traffickers go free (van Reisen et al., 2014; Human Rights Watch, 2014). Even though the anti-terrorism activities in North Sinai led to actions close to the encampments of the kidnappers, no effective actions were taken to free the hostages (until the fourth quarter of 2014, when socalled "torture-houses" in the Rafa area in North Sinai were destroyed). According to Human Rights Watch (2014) senior Egyptian officials are involved in the trafficking. During two hearings held in the European Parliament in the presence of the present authorsmeetings which were attended by Egyptian official representatives-it was found that responsibility was denied. Human Rights Watch found that to the extent that the reality in Sinai is acknowledged, the official position is that there is not enough evidence to investigate. Human Rights Watch (2014) concluded that only one person was prosecuted for Sinai Trafficking (an accomplice) in December 2013. This impunity should be seen in light of the widespread public knowledge of the Sinai Trafficking, the severity of the abuses, and the fact that these problems were raised at high diplomatic levels.

\subsection{Framing Sinai Trafficking in the Legal Framework of Trafficking in Persons}

The modus operandi of the traffickers and definition of Sinai Trafficking are distinct and deviate from the understanding of the notion of trafficking hitherto. This has profound implications for a legal understanding of the problem in two ways; first the combination of trafficking practices already known, e.g., trafficking for the purpose of slavery, and new forms of trafficking, namely trafficking for forced begging and ransom. Second, the interconnection between various serious crimes, including smuggling, abduction, extortion, slavery, torture, systematic sexual violence and killing. Like other forms of trafficking, Sinai Trafficking often starts as a process of human smuggling in which migrants willingly enter into an agreement with a smuggler to be moved from one place to another. Research has shown that migrants on the African continent only rarely have a clearly pre-established plan for the journey and the final destination is often determined by incidents during the migration process (Global Initiative against Transnational Organized Crime [GIATOC], 2014; Schapendonk, 2012; Terlinge \& Schramm, 2014). The migration journey can take several years with irregular intervals of traveling and temporary settlement to collect money for the next step in the migration process. Because these migrants are in dire need for money and lack a social network in the cities en route they are vulnerable to abusive and exploitative practices such as trafficking (GIATOC, 2014; Schapendonk, 2012). This is the junction where smuggling turns into a situation of trafficking. In the case of Sinai Trafficking the abusive and exploitative practices are of an extreme and unprecedentedly severe nature. Additionally, human trafficking generally takes place to exploit a person in labour or sexual services, which is not the case in Sinai Trafficking where the trafficking and torture takes place to extort people and to enforce the payment of ransom. This is not an obstacle to frame Sinai Trafficking into the trafficking framework as is argued below. Although trafficking is a crime often related to other crimes, the interconnectedness of the Sinai Trafficking with torture and other cruel and inhumane practices including sexual violence seems more ingrained in the way hostages and Eritreans specifically are treated in Sinai. The systematic torture, the severity and range of human rights violations and the aim of the whole process (the payment of ransom through abduction and extortion) makes Sinai Trafficking a specific form of trafficking not noted on a similar scale anywhere else in the world. At the same time, the overlaps that exist with other crimes, begs for a justification of it being framed as human trafficking.

\subsubsection{The Aim of Exploitation}

Internationally trafficking has been defined in the Palermo Protocol as: "Trafficking in persons shall mean the recruitment, transportation, transfer, harbouring or receipt of persons, by means of the threat or use of force or other forms of coercion, of abduction, of fraud, of deception, of the abuse of power or of a position of vulnerability or of the giving or receiving of payments or benefits to achieve the consent of a person having control over another person, for the purpose of exploitation".

This definition includes the three elements of trafficking; recruitment, force and aim of exploitation. Given the modus operandi described above, the elements of recruitment and force (including abduction) are easily established in the context of Sinai Trafficking. This seems to be more complicated for the third element; the aim of exploitation. In the Palermo Protocol exploitation is described but not defined, and shall "include at a minimum the exploitation of the prostitution of others or other forms of sexual exploitation, forced labour or services, slavery or practices similar to slavery, servitude or the removal of organs". As substantiated above, the continuing claims that the removal of organs is one of the aims of Sinai Trafficking has not been convincingly proven so far. The modus operandi and 
the different forms of human rights abuse of Sinai Trafficking combined with the lack of internationally defined criteria to define exploitation make it hard to determine to what extent these practices qualify as exploitation in the context of trafficking. Exploitation of persons seems to include some form of involuntariness and the practices mentioned above that "at a minimum" could be considered as exploitation seems to include a form of force or coercion. However, in relation to Sinai Trafficking the torturing and inhumane treatment is not related to work, sex work or provision of services but pressures family and relatives to pay the ransom. Extortion, beating and rape as a means to enforce payment of debts have anecdotally been reported in relation to Nigerian women trafficked for sexual exploitation and smuggling by Chinese snakeheads (Carling, 2005, pp. 41-53; Chu, 2011; Keefe, 2009) and forced extortion is for instance included in the description of "exploitation" in the Thai anti-trafficking law, more specifically, section 4 of the 2008 Anti-Trafficking in Persons Act, but, have never been considered an explicit element of the trafficking process internationally.

A first way of framing these practices into the trafficking legal framework is through the qualification of slavery. International law including human rights law, has defined and interpreted some of the forms of exploitation listed above. In the Slavery Convention of 1926 slavery is defined as "the status or condition of a person over whom any or all of the powers attaching to the right of ownership are exercised". It has long been advocated that this definition solely referred to the de jure ownership over a person, a practice that no longer exists in any country. Increasingly, the condition of ownership is understood to refer to de facto ownership addressing the actual situation of ownership which is present in many trafficking cases including in Sinai Trafficking where people are sold and resold as if they were the trafficker's property (Allain, 2009; van Reisen et al., 2014). In favour of this interpretation, Bales and Soodalter have defined ownership as "the complete control of one person by another, through the use of violence, both physical and psychological" (Bales \& Soodalter, 2009). In addition Allain and Bales, relying on the fundaments of property law, find grounds to focus on the factual situation in which a person is deprived of individual liberty to establish slavery (Allain \& Bales, 2012). Although this interpretation is not settled practice yet, it is gaining ground and the described practices of Sinai Trafficking where persons are treated as one's property and not as human beings justifying the use of the term slavery to fulfil the element of "aim of exploitation" in relation to Sinai Trafficking. In (rare) interviews or transcripts of negotiations recorded with hostage-owners, the language reveals the sense of commodity ownership they have and how their human "assets" are treated as tradable commodities.

A second way of framing the Sinai practices within the trafficking legal discourse is by qualifying the practices as forced labour or services. Taking the definition in the ILO convention on forced labour (Convention 29, 1930; "all work or service which is exacted from any person under the menace of any penalty and for which the said person has not offered himself voluntarily") it is not obvious that these practises do qualify as such because work is generally not performed at the places in Sinai where people are held hostage. The new protocol to the ILO forced labour convention, adopted 11 June 2014 reconfirms that forced labour shall include trafficking in persons for the purpose of forced or compulsory labour without altering the definition. With the adoption of directive 2011/36 on Trafficking of Human Beings (THB), the EU has included begging as a form of forced labour or services. Without a generally accepted definition of what characterises a situation as exploitative, Cherneva refers to a number of influential scholars, international organisations and experts who do consider forced begging as a form of exploitation in the realm of THB (Cherneva, 2011, p. 40). Cherneva is in favour of including forced begging as a separate category of trafficking in person, independent from labour trafficking. She argues that "begging could be discussed as a slavery-like practice" although it is more often subsumed "under the larger umbrella of forced labour" (Cherneva, 2011, pp. 42-43). In her study, begging is defined as the activity of asking for money as charity on the street. These are the practices the EU mentioned as well when it adopted begging as a form of forced labour or services as an exploitative practice, which are different from the practices of begging in $\mathrm{Si}$ nai Trafficking described above. However, the extortion of money combined with the forced begging for money for the release from the torture camps can be seen as a specific form of begging.

A third argument to apply the trafficking legal discourse to the situation of Sinai Trafficking is the situation of debt bondage in which many of the refugees find themselves. In the Supplementary Convention on the Abolition of Slavery, the Slave Trade, and Institution and Practices Similar to Slavery, debt bondage is considered a practice similar to slavery, and it falls within the scope of the description of exploitation within the Palermo Protocol.

A fourth reason why the practices in Sinai qualify as trafficking is that the description of forms of exploitation in the Palermo Protocol includes the phrase "at the minimum". Consequently, other exploitative practices than indicated in art. 1(3) can be relevant in the context of human trafficking. No further criteria have been given for further definition as such, exploitation remains undefined. Many scholars have convincingly argued that a diverse range of forms of exploitation can be accommodated under exploitation, and that it can be an aim for which the forced recruitment or transfer (the first element in the trafficking definition) 
is undertaken. In the context of Sinai Trafficking the extortion of hostages with the ultimate aim of the payment of ransom emerges as a new form of trafficking.

Summarizing the above, the argumentation to apply the trafficking legal framework is built on two lines of reasoning. First, Sinai Trafficking includes forms of exploitation that are explicitly described in the Palermo protocol, namely, slavery and in some cases debtbondage. Secondly, Sinai Trafficking has revealed new forms of exploitation as ultimate aims of the trafficking process, namely, the payment of ransom and forced begging. The latter has been recognised as an exploitative practice in the trafficking context at the European continent, but due to the torturing practices invigorating the forced begging it is of a different nature in the context of Sinai Trafficking.

\subsubsection{Interrelatedness with Other Severe Crimes}

The sexual abuse of women and men in Sinai Trafficking raises the questions of whether this can be qualified as sexual exploitation as described in the list of exploitative practices at which the trafficking process is aimed. Gallagher acknowledges that the failure to define sexual exploitation by the committee drafting the Palermo Protocol is problematic especially because of the complex and emotional dichotomy between those who consider prostitution as inherently exploitative, and those who consider voluntary prostitution an option (Gallagher, 2010, p. 38). However, this leaves us with a lack of parameters to define sexual exploitation, which complicates the framing of Sinai Trafficking. In the specific context of humanitarian law, practices of sexual violence and sexual exploitation have been considered an international crime. More specifically, it has been defined as a crime against humanity under enslavement in the Kunarac judgement of the ICTY. A similar situation would likely be qualified as a war crime under sexual slavery (Gallagher, 2010, p. 209). However, such qualifications require either a situation of war (in cases of war crimes) or they need to be part of a widespread or systematic attack against a civilian population (in cases of crimes against humanity), which is not per se present in the context of Sinai Trafficking.

Sinai Trafficking has many different faces and, unfortunately, it is not merely limited to the crime of trafficking. Torture, smuggling, rape and killing are just some of the crimes that are associated with Sinai Trafficking. The crime of trafficking is often committed together with other severe crimes (Organization for Security and Co-operation in Europe [OSCE], 2013), but in the case of Sinai Trafficking the purpose of the trafficking is slavery and extortion through severe torture. The kidnapping, locking up and the severe and extreme forms of violence and torture define the lives of the refugees in Sinai. In the case of Sinai Trafficking the severe violence amounts to torture and seems to be en- demic and part of the modus operandi with the ultimate aim of the collection of ransom, although torture without such aim and employed by sadistic individuals is reported as well (van Reisen et al., 2012, p. 81). Without going into the elements of torture, the relatedness between torture and trafficking will be briefly discussed here (OSCE, 2013). The use of force in the context of human trafficking easily turns into a form of torture or of ill and degrading treatment. Imagine practices in which people are locked up, have to work for more than 14 hours a day and live in unhealthy circumstances without running water. Cases in which women are forced into prostitution are even considered more easily as torture or as ill and degrading treatment because their physical integrity is at stake (OSCE, 2013). Torture in Sinai Trafficking is used to increase the pressure on refugees to collect the ransom and to pay off the debt and it is also a separate crime committed together with the crime of trafficking. The jus cogens character of the prohibition of torture makes it binding for all states irrespective of whether they have ratified relevant treaties. In international law one of the elements of the definition of torture is that it is performed by a state official. The violence and torture in case of Sinai Trafficking is generally committed by private individuals and not by state officials. Situations in which torture occurs with the acquiescence of a state official are covered by the definition and they trigger positive obligations based on due diligence for a state, which makes the state responsible for the torture (OSCE, 2013). The involvement of and systematic negligence of the situation by state officials as repeatedly reported by the authors (van Reisen et al., 2012; van Reisen et al., 2014) and others (Al, 2013; HRW, 2014) qualify the situation as torture, and the states involved bear responsibility. The traffickers involved are accountable for the violence incurred and for the trafficking practices to the extent they are covered by national laws prohibiting THB.

The organization and planning of Sinai Trafficking needs to be further investigated in the context of international humanitarian law and especially as a crime against humanities. The negligence of state parties to act in the domains of prevention, prosecution and protection must also be further examined as well as the participation of state parties in the organisation of elements of the Sinai Trafficking. The policy implications of the combat of trafficking and its ramifications for international cooperation are profound. Finally more research is needed to understand the potential "development" of this "business model" as a profitable industry and the possibility for it to extend to other places. This is especially relevant in light of its collusion with other areas of organized crime. This could potentially have profound consequences for stability and governance in other countries in the region and further afield, where international organized crime networks linked to this profitable model have a presence. 


\section{The Concept of the Human Trafficking Cycle}

Another aspect that is related to the Sinai Trafficking as it currently exists is the way in which victims become locked in a vicious cycle of trafficking. For those who originate from Eritrea the practice of forced labour in Eritrea is the first stage of the trafficking cycle. In Eritrea, people are recruited and obliged to serve in national service, sometimes for an indefinite period of time without any payment and without the option to refuse or leave national service (Kibreab, 2009). These recruits are forced to work on the land or in construction, for instance. If people flee Eritrea, they are likely to end up in refugee camps in neighbouring countries where they run the risk of being kidnapped, recruited or lured by smugglers or traffickers. The aim of the smuggling and trafficking is financial gain, which is achieved by forcing people to beg for money from their relatives, extended family or other people or by selling and re-selling people as if they were commodities. As argued above these practices are considered a second form of trafficking and a second stage of the trafficking cycle. If people manage to survive the Sinai and escape to another country or a safer place in Egypt, they run the risk of being subjected to yet another form of human trafficking. Sinai survivors are often detained by the Egyptian authorities and forced to beg for money in order to be released from prison and deported from Egypt. In Israel, Sinai survivors are also put in detention centres or left illegally on the streets without any means of income or support. In Egypt and other countries, Sinai survivors are often destined to live a life in illegality without any future perspective and without their stay ever being regularised. It is well recognised that people in such situations either in Israel, EU countries or other countries of destination easily fall victim to exploitative practices, which in many cases also qualify as human trafficking (European Agency for Fundamental Rights, 2011). These refugees then find themselves in the third stage of the trafficking cycle. The concept of the Human Trafficking Cycle provides an alternative to push and pull theories of migration, which appear inadequate to explain the (almost) infinite circular nature of Sinai Trafficking.

The analysis of the routes of survivors of Sinai Trafficking have highlighted the phenomenon of circles closing in on survivors and further reducing their future options. The fence constructed between Israel and Egypt in 2012 has stopped survivors seeking refuge in Israel, despite the proximity of the locations where the refugees are held captive and despite the knowledge of the Israeli government of the location of these socalled "torture houses". The interviews show clear signs of extremely violent push backs of survivors of Sinai Trafficking, even in humanitarian cases of pregnant women, children or generally physically exhausted and wounded survivors. The interviews demonstrate without doubt the collusion of Israeli military with Egyptian military around the border area. This practice is referred to as "coordinated returns" by the Israeli government (Hotline for Migrant Workers, 2012).

\subsection{Israel}

The situation in Israel is dominated by the "AntiInfiltration Law", amended in 2012 to include African migrants, which defines "all irregular border-crossers as 'infiltrators'" (Human Rights Watch, 2012). The law makes all irregular border crossings illegal and punishable by detention. This also affects Sinai Trafficking survivors, asylum-seekers and children (Kritzman-Amir \& Spijkerboer, 2013). Those charged with irregular bordercrossing can be kept in detention for a period of three years or more, which can be followed by deportation; the law even allows for indefinite detention, even in the face of potential persecution if they would be returning to their home-country (van Reisen et al., 2014). Being coined as "infiltrators" by media, politics and law, the Sinai survivors are held in locations subject to dispute by the highest legal authorities in Israel. In these detention centres and "open" facilities there is a high level of deep despair among the refugees. There is a lack of basic facilities, no access to trauma treatment for survivors of torture, and lack of access to protection under national law. This desperate situation results in a high degree of suicide attempts and hunger strikes seen as the only way of dignity for survivors who try to define their own fate (van Reisen et al., 2014). The Hotline for Refugee and Migrant Workers (2014) is the only organization with access to these facilities and it has reported widely on the draconian situation in which these survivors of Sinai Trafficking find themselves. The citations of interviews printed by the Hotline to illustrate the severity of the situation are all of Eritrean refugees, pointing once more to the specific vulnerability of Eritrean refugees to be trapped in a cycle of despair in the current circumstances of their country and regional realities. These interview excerpts point to the abuse by Israeli authorities of refugees (among whom there were Sinai Trafficking survivors): “On Sunday around 6pm we were encircled by police and immigration officers. They had horses, water cannon trucks, many cars and over seven buses. One of the officers told us by megaphone that we had five minutes to go peacefully to the buses. We told them that we had questions that need to be addressed, so we requested them to give us time and a responsible person who could answer our demand. They refused to listen to us and they started to take people by force....It became difficult for us to stay strong when they started to spray our eyes....Even though I was not beaten I saw the police attacking people, kicking and punching them. Especially after it became dark or in places where there were no cameras, they beat many people very badly. I saw people becoming unconscious, falling on the ground and taken to the ambulance". (7 August 2014). 


\subsection{Egypt}

Egypt has a good legal framework with Law 64 adopted in 2010 to combat Human Trafficking. The legal framework on human trafficking defines measures for prevention, protection and prosecution. However, there is a serious lack of implementation of this legal framework in all of these areas. The survivors of Sinai Trafficking are put in prison in Egypt in detention centres, without charge and access to legal process. Survivors, who are often traumatized due to the torture, rape and abuse they suffered during their captivity, do not receive physical or psychological support or healing treatment, nor do they receive access to legal aid. In order to be able to leave the detention centres, the Sinai survivors are obligated to collect money to pay a return flight for their deportation to Eritrea-the country from which they fled-or Ethiopia.

The situation in Israel and Egypt is described as examples of the situation in which the Sinai Trafficking survivors find themselves trapped. Despite the UNHCR providing clear guidelines on the obligation of the international community to protect Eritrean refugees, the situation in the countries where they look for protection does not offer them a secure situation. The survivors of Sinai Trafficking find themselves in a vicious circle. The research concludes that the concept of the "Sinai Trafficking cycle" offers a way of examining and understanding "the circular and closed system in which the refugees are trapped" (van Reisen et al., 2014, p. 147). The Sinai Trafficking cycle, in the context of the majority of survivors being of Eritrean origin, is described from a perspective of the refugee as follows: "Once in the trafficking cycle, there is no way out for these refugees. Persecuted and enslaved in their own country, they flee to refugee camps where they risk being recruited or abducted for trafficking and torture in Sinai. If they survive the Sinai, they face detention or refoulement to the country they tried to escape from, or are forced to take even greater risks to try to reach safety. They have little chance of being granted asylum-if this option is even available. They also find themselves with little options for regularizing their irregular status in the host country and live on the fringes of society, which again leaves them vulnerable to exploitation and trafficking" (van Reisen et al., 2014). The legal consequences and policy ramifications of this understanding need to be further examined. There is also a need to further increase the understanding of whether other countries in the region and further afield, including those in the EU, are part of the Human Trafficking cycle, or not and if so, how.

\section{Conclusions}

In this article the phenomenon coined "Sinai Trafficking" has been further contextualised by discussing the background of the phenomenon, the trafficking legal framework and the role of other countries. As is clear from this discussion and analysis, further research is required to enhance the understanding of the various implications of Sinai Trafficking. Follow-up on the modus operandi will need to be continued because the traffickers adjust their activities to increase profits. Policies in surrounding countries have direct implications for the modus operandi of the traffickers and directly affect the situation of the refugees as has been illustrated by the example of the fence on the IsraeliEgyptian border. Further research on the responsibility and policies of countries of destination, including countries in the EU as well as the EU itself, needs to address these consequences.

The practices described in this article dehumanize the victims, intentionally causing great suffering and serious bodily and mental injury and the physical and psychological effects of the violence, torture and trafficking endured will be something Sinai survivors carry for the rest of their lives. Victims are subject to extreme sexual violence, rape and forced pregnancy (in case of women). The victims are ethnically selected, with the vast majority being of Eritrean origin. So far the justice-systems have failed in putting an end to these practices and in persecution of the main perpetrators of these crimes. In order to better understand the chain of responsibility for these crimes, further research is needed. Moreover, to ensure that destination countries will take due account of the trauma and other consequences of these horrendous practices, further research on the trauma and situation of Sinai survivors is required, especially in light of the established cycle of trafficking that is described in this article as associated with Sinai Trafficking.

To conclude, Sinai Trafficking is a specific form of trafficking characterised by a combination of different forms of trafficking such as trafficking for slavery, and forced begging and in which the use of severe violence and torture is utilized to invigorate the extortion of ransom, which can be labelled a new form of trafficking, namely, trafficking for the payment of ransom. Moreover, the relation with other forms of crime, e.g., smuggling, torture and sexual violence is another distinctive element of Sinai Trafficking. It is called Sinai Trafficking because these practices have first been detected on a large scale in Sinai but unfortunately they are not limited to the Sinai desert. First indications that the same modus operandi is employed in areas outside Sinai have been communicated in some of the interviews. Research on the extent to which these practices occur in other countries or regions is needed, preferably before it becomes a large scale established practice as was the case in Sinai.

\section{Acknowledgements}

The authors acknowledge the financial contribution of 
the Dutch Interchurch Organisation for Development (ICCO) in support of the research undertaken for this article.

\section{Conflict of Interests}

The authors declare no conflict of interests.

\section{References}

Allain, J., \& Bales, K. (2012). Slavery and its definition (Queen's University Belfast Law Research Paper, no. 12-06). Retrieved from http://papers.ssrn.com/ sol3/papers.cfm?abstract_id $=2123155$

Allain, J. (2009). R v. Tang: Clarifying the definition of "slavery" in international law. Melbourne Journal of International Law, 10(1), 246-257.

Amnesty International. (2013). Egypt/Sudan. Refugees and asylum-seekers face brutal treatment, kidnapping for ransom and human trafficking. London: Amnesty International.

Bales, K., \& Soodalter, R. (2009). The slave next door: Human trafficking and slavery in America today. Berkeley: University of California Press.

Carling, J. (2005, July 1). Trafficking in women from $\mathrm{Ni}$ geria to Europe. Migration Policy Institute. Retrieved from http://www.migrationpolicy.org/ article/trafficking-women-nigeria-europe/

Carr, S. (2011, December 6). Rights groups: Hundreds of refugees held hostage in Sinai "torture camps". Egypt Independent. Retrieved from http://www. egyptindependent.com/news/rights-groups-hundred s-refugees-held-hostage-sinai-torture-camps

Cherneva, I. (2011). Human trafficking for begging. Buffalo Human Rights Law Review, 17, 25-51.

Chu, C. Y. (2011). Human trafficking and smuggling in China. Journal of Contemporary China, 20, 39-52.

CNN. (2011, November 19). Death in the desert: A CNN freedom project documentary. CNN.

CNN. (2012, September 21). A stand in the Sinai. A CNN Freedom Project Documentary. CNN.

European Agency for Fundamental Rights. (2011). Fundamental rights of migrants in an irregular situation in the EU. Luxembourg: FRA. Retrieved from http: //fra.europa.eu/en/publication/2012/fundamentalrights-migrants-irregular-situation-european-union

European Parliament. (2010). Hearing on refugees, child soldiers and European policy. Hosted by Judith Sargentini (MEP).

Gallagher, A. T. (2010). The international law of human trafficking. Cambridge: Cambridge University Press.

GIATOC. (2014). Smuggled Futures: The dangerous path of the migrant from Africa to Europe (Research Report). Geneva, Switzerland: Global Initiative against Transnational Organized Crime.

Hotline for Migrant Workers. (2012). Written submission pre-session of the $2^{\text {nd }}$ periodic review commit- tee of the right of the child. Tel Aviv, Israel: Hotline for Migrant Workers.

Hotline for Migrant Workers, \& Physicians for Human Rights. (2012, April). Briefing note: Israeli treatment of African asylum-seekers and refugees arriving in Israel via Sinai. Retrieved from http://www.phr.org. il/default.asp?PagelD=100\&/temID=1549

Hotline for Refugees and Migrant Workers. (2014, July 8). Israeli authorities use unnecessary force to quash protest of detained asylum seekers [Press Release]. Retrieved from http://eritreanhuman rights.org/index.php?option=com_content\&view=c ategory\&layout $=$ blog\&id $=68 \&$ Itemid $=336$

Human Rights Watch. (2012, June 10). Israel: Amend "Anti-Infiltration" Law: Measure denies asylum seekers protections of refugee convention. Retrieved from http://www.hrw.org/news/2012/06/ 10/israel-amend-anti-infiltration-law

Human Rights Watch. (2014, February 11). I wanted to lie down and die. Trafficking and torture of Eritreans in Sudan and Egypt. New York, NY: Human Rights Watch. Retrieved from http://www.hrw. org/sites/default/files/reports/egypt0214_ForUplo ad_1_0.pdf

Humphris, R. (2012). Refugees and the Rashaida: Human smuggling and trafficking from Eritrea to Sudan and Egypt (Research paper no. 247). Geneva, Switzerland: UNHCR.

Keefe, P. R. (2009). Snakeheads and smuggling. The dynamics of illegal Chinese immigration. World Policy Journal, 26, 33-44.

Kibreab, G. (2009). Forced labour in Eritrea. Journal of Modern African Studies, 47(1), 41-72.

Kritzman-Amir, T., \& Spijkerboer, T. (2013). On the morality of legality of borders: Border policies and asylum seekers. Harvard Human Rights Journal, 26, 138.

Mekonnen, D. R., \& Estefanos, M. (2012). Asmarino. Retrieved from http://asmarino.com/articles/1411from-sawa-to-the-sinai-desert-the-eritreantragedy-of-human-trafficking6

OSCE. (2013). Part I: Trafficking in human beings amounting to torture and other forms of illtreatment; Part II: Clinical links between human trafficking and torture (Occasional paper series, no. 5). Vienna: Organization for Security and Cooperation in Europe. Retrieved from https://www. osce.org/cthb/103085

Physicians for Human Rights. (2010a). Refugees, torture, and rape in Sinai Desert: A PHR-Israel update about recently arriving asylum-seekers (Report). Israel: Physicians for Human Rights.

Physicians for Human Rights. (2010b). Refugees, torture, and rape in Sinai Desert: A PHR-Israel update about recently arriving asylum-seekers [Press release]. Israel: Physicians for Human Rights.

Physicians for Human Rights. (2011, February 23). Hos- 
tages, torture, and rape in the desert: Findings from 284 asylum seekers about atrocities in the Sinai. Retrieved from http://www.phr.org.il/uploaded/Phrisrael-Sinai-Report-English-23.2.2011.pdf

Physicians for Human Rights-Israel, Hotline for Migrant Workers, Agenzia Habeshia, International Commission on Eritrean Refugees, The America Team for Displaced Eritreans, Eritrean Movement for Democracy and Human Rights, \& Release Eritrea. (2012, March 31). Hundreds of refugees held hostage in Sinai torture camps need rescuing (Report). Retrieved from http://www.phr.org.il/default.asp?PagelD=18 3\&ItemID=1176

Pleitgen, J. (2011, November 3). Refugees face organ theft in Sinai. CNN.

Reisen, van M., Estefanos, M., \& Rijken, C. (2012). Human trafficking in the Sinai: Refugees between life and death. Oisterwijk, Netherlands: Wolf Publications.

Reisen, van M., Estefanos, M., \& Rijken, C. (2014). The Human Trafficking Cycle: Sinai and beyond. Oisterwijk, Netherlands: Wolf Publications.

Schapendonk, J. (2012). Mobilities and sediments: Spa- tial dynamics in the context of contemporary SubSaharan African migration to Europe. African Diaspora, 5, 117-142.

Terlinge, S., \& Schramm, E. (2014, December 5). Met een Smokkelaar naar Ter Apel. One World. Retrieved from http://www.oneworld.nl/wereld/meteen-smokkelaar-naar-ter-apel

UN Monitoring Group on Somalia and Eritrea. (2011). Report of the Monitoring Group on Somalia and Eritrea pursuant to Security Council Resolution 1916 (2010) (S/2011/433). New York: United Nations Security Council.

UN Monitoring Group on Somalia and Eritrea. (2012). Report of the Monitoring Group on Somalia and Eritrea pursuant to Security Council resolution 2002 (2011). New York: United Nations Security Council.

UN Monitoring Group on Somalia and Eritrea. (2013). Report of the Monitoring Group on Somalia and Eritrea pursuant to Security Council resolution 2060 (2012). New York: United Nations Security Council.

VoMD. (2011). Interview with Eritrean hostages in Sinai (Egypt) by Meron Estefanos. Retrieved from https://www.youtube.com/watch?v=CzzNMOQg1Lo

\section{About the Authors}

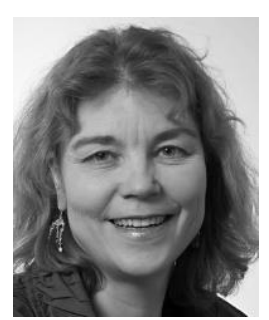

\section{Dr. Mirjam van Reisen}

Mirjam van Reisen is Professor International Social Responsibility and Marga Klompé Chair at Tilburg University, School of Humanities, Member of the Dutch Council on Foreign Affairs, and Chair of the statutory Commission on Development Cooperation. She is founding Director of Europe External Policy Advisors based in Brussels. She teaches at Amsterdam University College.

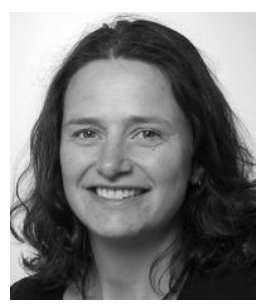

\section{Dr. Conny Rijken}

Conny Rijken is Associate Professor at Intervict (International Victimology Institute) at Tilburg Law School, and has specialised in human trafficking in relation to human rights and migration at Tilburg University. She is member of the Advisory Committee on Migration Affairs, which reports and advises the Dutch government on migration policy issues. 